\section{Effect of food on the} pharmacokinetics of the oral phosphodiesterase 5 inhibitor udenafil for the treatment of erectile dysfunction

Tae-Eun Kim, Bo-Hyung Kim, Jung-Ryul Kim, Kyoung Soo Lim, Jang Hee Hong, ${ }^{1}$ Kyu-pyo Kim, Hwa-Sook Kim, Sang-Goo Shin, In-Jin Jang \& Kyung-Sang Yu

Department of Pharmacology and Clinical Pharmacology, Seoul National University College of Medicine and Hospital, Seoul and 'Department of Pharmacology, Chungnam National University College of Medicine, Daejeon, Korea

\section{Correspondence}

Professor Kyung-Sang Yu, MD, PhD, Department of Pharmacology and Clinical Pharmacology, Seoul National University College of Medicine and Hospital, 101 Daehangno, Jongno-gu, Seoul 110-744, Korea.

Tel: + 82220721920

Fax: + 8227457996

E-mail:ksyu@snu.ac.kr

\section{Keywords}

food, pharmacokinetics,

phosphodiesterase type 5 inhibitor udenafil

\section{Received}

16 June 2008

Accepted

22 February 2009

\section{WHAT IS ALREADY KNOWN ABOUT}

\section{THIS SUBJECT}

- Udenafil is a newly marketed

phosphodiesterase type 5 (PDE5) inhibitor.

- Udenafil is safe and well tolerated in healthy

subjects, and effective as treatment for

erectile dysfunction.

- The effect of food on the pharmacokinetics of PDE5 inhibitors varies.

\section{WHAT THIS STUDY ADDS}

- This is the first study to determine the effect of food on the pharmacokinetics of udenafil.

- Food generally does not affect the

bioavailability of udenafil, although a low-fat diet shows a tendency to decreases the absorption rate of udenafil.

\section{AIMS}

Udenafil is a cyclic guanosine $3^{\prime}, 5^{\prime}$-monophosphate-specific

phosphodiesterase type 5 (PDE5) inhibitor developed for the treatment of erectile dysfunction. The aim was to evaluate the effect of food on the pharmacokinetics of udenafil.

\section{METHODS}

An open, randomized, three-way crossover study was conducted. Fifteen healthy male volunteers received a single 200-mg oral dose of udenafil while fasting, after a low-fat meal, and after a high-fat meal separated by 7-day washout periods. Serial blood samples were taken up to $48 \mathrm{~h}$ after oral administration.

\section{RESULTS}

Under fasting conditions, udenafil was rapidly absorbed and $t_{\max }$ was observed typically $1.5 \mathrm{~h}$ after administration. The mean $t_{\max }$ values after a low-fat meal and a high-fat meal were 2.6 and $2.1 \mathrm{~h}$, respectively. The ratios ( $90 \%$ confidence intervals) of the geometric means compared with the fasting condition for $C_{\max }$ and $A \cup C_{\text {last }}$ were $0.79(0.70,0.90)$ and $0.96(0.89,1.03)$ in the low fat-fed condition, respectively, and $1.01(0.89$, $1.15)$ and $1.03(0.96,1.11)$, respectively, in the high fat-fed condition.

\section{CONCLUSIONS}

The $t_{\max }$ of udenafil was delayed under the fed conditions. However, although the $C_{\max }$ was reduced by approximately $21 \%$ in the low fat-fed state, overall bioavailability was not affected when taken with food. 


\section{Introduction}

The phosphodiesterase 5 (PDE5) inhibitor maintains penile erection by inhibiting the hydrolysis of cyclic guanosine $3^{\prime}, 5^{\prime}$-monophosphate, which plays an important role in erection. Udenafil (Zydena ${ }^{\circledR}$; Dong-A Pharmaceutical Co., Seoul, Korea) is a PDE5 inhibitor developed as a medical treatment for erectile dysfunction. Having a molecular structure similar to that of sildenafil, it has been found that udenafil is comparable to sildenafil citrate in terms of selectivity for PDE5 [1]. Previous Phase I clinical study data show that udenafil has a longer drug exposure in comparison with other drugs of similar mechanism $[2,3]$, since it has a time to maximum drug plasma concentration of $0.8-$ $1.3 \mathrm{~h}$, and a terminal elimination half-life of 7.3-12.1 h [4].

It has been demonstrated that food intake simultaneous with or just before drug administration can affect drug pharmacokinetics. Udenafil is likely to be taken with food, and modification of the dosing regimen may be required in the event of any subsequent significant change in the pharmacokinetics. Therefore, we examined the effect of food on the pharmacokinetics of udenafil by administering it after fasting and low-fat and high-fat meals.

\section{Methods}

Fifteen healthy male volunteers were studied as per a protocol approved by the Institutional Review Board of Seoul National University Hospital after obtaining written informed consent. The mean (SD) age of the subjects was 25.2 (4.6) years, and the mean height and weight were $174.3(4.8) \mathrm{cm}$ and $69.4(7.9) \mathrm{kg}$, respectively.

This study was conducted in a randomized, open-label, three-treatment, three-sequence crossover design. The subjects were randomly assigned to one of three sequence groups (fasting-low-fat meal-high-fat meal, low-fat mealhigh-fat meal-fasting, and high-fat meal-fasting-low-fat meal), with five subjects in each group. During each study session, subjects received a single 200-mg oral dose of udenafil within $30 \mathrm{~min}$ after the start of eating in the case of the low-fat or high-fat meal conditions. The caloric contents of the low-fat and high-fat meal were $600 \mathrm{kcal}$ and $900 \mathrm{kcal}$, respectively, according to the recommendations of US Food and Drug Administration guidance [5] and also a domestic guideline [6]. Sixty percent of the calories in the low-fat meal were derived from carbohydrate, $20 \%$ from protein, and $20 \%$ from fat. In the high-fat meal, $30 \%$ of the calories were derived from carbohydrate, $15 \%$ from protein, and $55 \%$ from fat.

Venous blood samples $(8 \mathrm{ml})$ were taken at predose $(0 \mathrm{~h})$ and at $0.5,1,1.5,2,2.5,3,4,6,8,12,24,32$ and $48 \mathrm{~h}$ after drug administration. The udenafil concentration in plasma was determined by using liquid chromatography-tandem mass spectrometry. Intra- and interday accuracy ranged from 97.4 to $102.3 \%$, and intra- and interday precision,

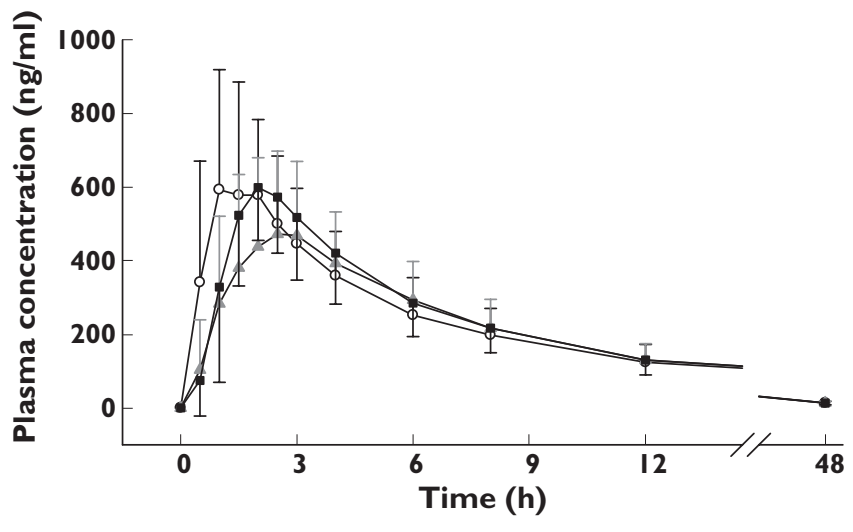

\section{Figure 1}

Mean plasma concentration-time profiles of udenafil after oral administration of udenafil $200 \mathrm{mg}$ to 15 healthy male volunteers under fasting, low-fat meal and high-fat meal conditions, respectively. Bars represent standard deviations. fasting ( $(-\bigcirc)$; low-fat meal ( $-\triangle-$ ); high-fat meal (- - -)

expressed as the percent coefficient of variation, was $<4 \%$, providing evidence that the plasma concentration analysis method had reliability over the given range.

Pharmacokinetic analysis was performed by noncompartmental evaluation using WinNonlin ${ }^{\circledR}$ (Version 5.1; Pharsight Co., Mountain View, CA, USA). Statistical analysis was performed using SPSS 12.0 (SPSS Inc., Seoul, Korea). The point estimate and $90 \%$ confidence interval $(\mathrm{Cl})[5,7]$ for the geometric mean ratio of the low fat-fed state to the fasting state and the high fat-fed state to the fasting state in log transformed $C_{\max }$ and $A \cup C_{\text {last }}$ were calculated by analysis of variance (ANOVA) using a mixed effects model fitting sequence, period and treatment as fixed effects and subject (sequence) as a random effect.

\section{Results}

Following the administration of udenafil under fasting conditions, $C_{\max }$ was achieved at $1.5 \mathrm{~h}$ after dosing, and udenafil was not detected in plasma $48 \mathrm{~h}$ after dosing. When udenafil was administered after food intake, $t_{\max }$ was delayed to $2.6 \mathrm{~h}$ after a low-fat meal and $2.1 \mathrm{~h}$ after a highfat meal, but exhibited a similar elimination profile to that of the fasting state thereafter (Figure 1, Table 1).

The pharmacokinetic parameters after a low-fat and a high-fat meal were compared with those of the fasting state. The geometric mean ratio between the low fat-fed state and the fasting state was $0.79(90 \% \mathrm{Cl} 0.70,0.90)$ for $C_{\max }$ and $0.96(0.89,1.03)$ for $A U C_{\text {last, }}$ showing no remarkable difference in the extent of drug absorption, although the $C_{\max }$ did decrease by $21 \%$ on average. The geometric mean ratio between the high fat-fed and fasting state was $1.01(0.89,1.15)$ for $C_{\max }$ and $1.03(0.96,1.11)$ for $A U C_{\text {last }}$ (Table 1), with no apparent differences in maximum 


\section{Table 1}

Mean plasma pharmacokinetic parameters of udenafil after 200-mg single oral administration under fasting, low-fat meal and high-fat meal conditions and geometric mean ratios of $C_{\max }$ and $A \cup C_{\text {last }}$ between the low-fat meal and fasting and between the high-fat meal and fasting conditions

\begin{tabular}{|c|c|c|c|c|c|}
\hline Parameter & Fasting & Low-fat meal & High-fat meal & $\begin{array}{l}\text { Geometric mean ratio }(90 \% \mathrm{Cl}) \\
\text { Low-fat meal/fasting }\end{array}$ & High-fat meal/fasting \\
\hline$C_{\max }\left(\mathrm{ng} \mathrm{ml}^{-1}\right)$ & $702.9 \pm 282.7$ & $560.5 \pm 215.1$ & $687.5 \pm 172.2$ & $0.79(0.70,0.90)$ & $1.01(0.89,1.15)$ \\
\hline$t_{\max }(\mathrm{h})^{*}$ & $1.5(0.5-2.5)$ & $2.6(1.0-4.0)$ & $2.1(1.0-3.0)$ & - & - \\
\hline$t_{1 / 2}(\mathrm{~h})$ & $12.8 \pm 1.2$ & $12.9 \pm 1.5$ & $12.4 \pm 1.3$ & - & - \\
\hline
\end{tabular}

Values represent the mean \pm SD except for $t_{\max .}{ }^{\star}$ Reported as the mean (range).

plasma drug concentrations and drug absorption between the high fat-fed and fasting states.

There were no significant differences between the treatment groups regarding adverse events, vital signs, laboratory tests, or 12-lead electrocardiograms (data not shown).

\section{Discussion}

This study was performed to examine the effect of food on the pharmacokinetics of udenafil, a PDE5 inhibitor developed for erectile dysfunction. As a high-fat diet frequently affects drug absorption, this study attempted to determine the maximum effect of food on the pharmacokinetics of udenafil by drug administration after a high-fat meal. It also evaluated the degree of alteration in the pharmacokinetics of udenafil after a low-fat meal, since a typical Asian diet has lower calories and low fat content. The differences in pharmacokinetics between fed conditions and the fasting condition were assessed by $t_{\max }, C_{\max }$ and AUC.

The findings of this study suggest that food does not have a significant influence on the extent of absorption of udenafil, whereas the delay of $t_{\max }$ and reduction of $C_{\max }$ indicate a decreased drug absorption rate by food intake. In the study, the amount of reduction in the absorption rate was found to be larger after a low-fat meal than after a high-fat meal, contradicting the general belief that a highfat diet has a greater effect on pharmacokinetics than a low-fat diet. The authors reason that this might have resulted from the lipophilicity of udenafil. In general, drugs with a high lipophilicity exhibit increased absorption when they are administered with a high-fat diet [8], which increases pancreatic and biliary secretion, resulting in an increased dissolution rate. Udenafil is lipophilic, displaying a $0.76-1.85$ octanol/water partition coefficient (Log P) in approximately $\mathrm{pH} 1$ to $\mathrm{pH} 7$ [9]. Thus, it can be inferred that the increased solubility by the high-fat meal was responsible for the higher absorption rate of udenafil compared with the low-fat meal, although the absorption rate was decreased overall compared with the fasting state.

In this study, the geometric mean ratio for $C_{\max }$ between the low fat-fed condition and fasting condition was 0.79 , with $0.70,0.90$ as the $90 \% \mathrm{Cl}$, which was slightly outside the range of 0.80 to 1.25 that suggests absence of food effect on bioavailability, generally [5]. However, considering that the amount of reduction in $C_{\max }$ was not great and also considering that the clinical effect is thought to be more closely related to the overall exposure to the drug, rather than the concentration itself $[9,10]$, these findings are not expected to influence the therapeutic effect.

In conclusion, there was little difference in the overall exposure of the drug, not implying any clinical significance. Thus, udenafil can be administered without any limitation of meal conditions, and a modification of dosing regimen is considered to be unnecessary.

\section{Competing interests}

None to declare.

This study was sponsored by Dong-A Pharmaceutical Company, Seoul, Korea (06-2006-027). The investigational site was Clinical Trials Centre, Seoul National University Hospital, Seoul, Korea.

\section{REFERENCES}

1 Doh H, Shin CY, Son M, Ko Jl, Yoo M, Kim SH, Kim WB. Mechanism of erectogenic effect of the selective phosphodiesterase type 5 inhibitor, DA-8159. Arch Pharmacal Res 2002; 25: 873-8.

2 Pfizer, Inc. Viagra [package insert]. New York: Pfizer, Inc, 2006. Available at http://www.fda.gov/cder/foi/label/ 2008/020895s026lbl.pdf (last accessed 14 March 2009).

3 Bayer Pharmaceuticals Corp. Levitra [package insert]. Leverkusen: Bayer Pharmaceuticals Corp, 2007. Available at http://www.fda.gov/cder/foi/label/2008/021400s011lbl.pdf (last accessed 14 March 2009).

4 Kim BH, Lim HS, Chung JY, Kim JR, Lim KS, Sohn DR, Cho JY, Yu KS, Shin SG, Paick JS, Jang IJ. Safety, tolerability and pharmacokinetics of udenafil, a novel PDE-5 inhibitor, in healthy young Korean subjects. Br J Clin Pharmacol 2008; 65: 848-54. 
5 US Department of Health and Human Services, Food and Drug Administration, Center for Drug Evaluation and Research. Guidance for Industry: Food-Effect Bioavailability and Fed Bioequivalence Studies. Rockville, MD: US Department of Health and Human Services, Food and Drug Administration, Center for Drug Evaluation and Research, 2002. Available at http://www.fda.gov/cder/ guidance/5194fnl.pdf (last accessed 14 March 2009).

6 Korean National Institute of Toxicological Research. Guideline on Food-Effect Bioavailability and Fed Bioequivalence Studies. Seoul: Korean National Institute of Toxicological Research, 2005. Available at http://kfda.go.kr/index2.html (last accessed 14 March 2009).

7 US Department of Health and Human Services, Food and Drug Administration, Center for Drug Evaluation and
Research. Guidance for Industry: Statistical Approaches to Establishing Bioequivalence. Rockville, MD: US Department of Health and Human Services, Food and Drug Administration, Center for Drug Evaluation and Research, 2001. Available at http://www.fda.gov/cder/guidance/ 3616fnl.pdf (last accessed 14 March 2009).

8 Singh BN. Effects of food on clinical pharmacokinetics. Clin Pharmacokinet 1999; 37:213-55.

9 Dong-A Pharmceutical Company. Zydena ${ }^{\circledR}$ (udenafil). Investigator's Brochure (Study Number: DA8159_DIF_I).

10 Paick JS, Kim SW, Yang DY, Kim JJ, Lee SW, Ahn TY, Choi HK, Suh JK, Kim SC. The efficacy and safety of udenafil, a new selective phosphodiesterase type 5 inhibitor, in patients with erectile dysfunction. J Sex Med 2008; 5: 946-53. 